\title{
Treatment of patellofemoral chondropathy with BIOART
}

\author{
Ferdinando Franzoni ${ }^{1 *}$, Jonathan Fusi ${ }^{1}$, Marco Ceccarelli ${ }^{2}$, \\ Andrea Petrocchi', Matteo Vitale ${ }^{2}$, Marco Letari' ${ }^{2}$, Riccardo \\ Banducci ${ }^{1}$, Veronica Santini ${ }^{1}$, Giorgia Scarfò ${ }^{1}$, Eugenio Cerri ${ }^{1}$ \\ and Fabio Galetta ${ }^{1}$
}

${ }^{1}$ Sport Medicine Unit, Department of Clinical and Experimental Medicine, University of Pisa, Italy

${ }^{2}$ Orthopedics Unit, Department of Clinical and Experimental Medicine, University of Pisa, Italy

Received: 03 February, 2020

Accepted: 02 December, 2020

Published: 03 December, 2020

*Corresponding author: Ferdinando Franzoni, Sport Medicine Unit, Department of Clinical and Experimental Medicine, University of Pisa, Italy, Tel: 050992408; E-mail: ferdinando.franzoni@unipi.it

Keywords: Patellofemoral syndrome; Chondropathy; Equine collagen

https://www.peertechz.com

\section{Check for updates}

\section{Abstract}

The patellofemoral syndrome is characterized by morpho-functional alterations, mainly caused by a misalignment or dysplasia of the patella and/or femoral trochlea. The treatment of this chondropathy is mostly conservative. Furthermore, clinical practice seeks to use "chondroprotective" drugs and supplements, capable of counteracting degenerative processes, favoring the normalization of articular cartilage and synovial fluid. However, to date there are no effective and lasting treatments aimed at restoring joint function.

Objective: The aim of the study is to evaluate the efficacy and tolerability of the medical device "Bioart", based on equine collagen, in patients suffering from patellofemoral chondropathy.

Results: All patients enrolled in the study $(\mathrm{N}=23)$ showed a consistent improvement in the algic component and functional limitation related to the chondro-arthrosic process within 12 weeks.

Conclusion: The data showed that Bioart is able to improve the clinical-functional picture of treated patients. Furthermore, the absence of side effects and cost reduction improved adherence to therapy.

\section{Abbreviations}

MSM: Methylsulfonylmethane; WOMAC: Western Ontario and McMaster Universities Osteoarthritis Index

\section{Introduction}

The patella is a sesamoid bone, roughly triangular in shape, placed inside the quadriceps muscle tendon. This bone, articulating with the trochlear groove of the femur, mechanically constitutes the fulcrum of extensor mechanisms of the lower limb. Both the articular surfaces of the patella itself and those of the trochlear sulcus are covered by an articular cartilage that is on average 4 to $6 \mathrm{~mm}$ thick $[1,2]$. The normal sliding mechanisms of the patellofemoral joint are controlled by static factors, i.e. non-contractile and dynamic, i.e. contractile. Static factors are represented by the patella size, femoral condyles and their size, the shape/angle of the trochlear sulcus and the alignment of the lower limb [3-6].

The patellofemoral syndrome is characterized by a set of morpho-functional alterations that determine the onset of an anterior knee. These functional alterations of the anatomical structures above and below, such as axial or rotational changes of the lower limb, or the morpho-functional alterations of the foot, can negatively influence the mechanics of the patellofemoral joint [6-12]. From an etiopathological point of view, the basis of the patellofemoral syndrome are alterations essentially attributable to a malalignment, or to a dysplasia of the patella and/or femoral trochlea [6-16]. In the field of patellofemoral syndrome, joint biomechanics plays a fundamental role. In fact, an abnormality of shape and/or position of the patella itself, has a direct relapse on its functionality, determining an altered sliding in the trochlear groove. A bad patellar sliding 
can lead to a cartilaginous alteration commonly referred to as "chondrosis" or "arthrosis", whose etiology is due to the action of compressive forces not adequately distributed over the entire surface of the patellofemoral joint itself. In particular, an increase in the amplitude of the flexion movements of the knee, which is found in many recreational-sports activities, increases the extent of compression forces at the patellofemoral level, and can cause an alteration of the articular surface, which can be found also in young individuals [15-19]. In 1964, Outerbridge had classified the articular cartilage lesions according to four different degrees: I degree characterized by softening and swelling less than $1 / 2$ inch $(1.27 \mathrm{~cm})$, II degree with fragmentation and fissuring minor than $1 / 2$ inch, III degree with fragmentation and fissure greater than $1 / 2$ inch $1.5 \mathrm{~cm}$, IV, the most serious, III degree with erosion of the cartilage in the direction of the subchondral bone.

From a clinical point of view, the patellofemoral syndrome is characterized by constant pain in the anterior part of the knee joint. Sometimes an antalgic pseudo-articular block may occur, but the amplitude of movement is however in most reduced. An important hypotonotrophy of the quadriceps muscle is often associated to this syndrome. In the process of chronicity, soft joint structures (such as the patellar tendon, the suprapatellar, prepatellar and anserine bag, the medial and lateral retinacula, the medial, lateral and superior folds, the saphenous nerve at the tubercle) can be involved of the adductors or tendon of the goose leg. At a clinical examination, pain is evoked requiring an isometric contraction, against resistance, in a range between 0 and $20^{\circ}$ of flexion. Conventional radiography, carried out in different angles of knee flexion and especially MRI, confirm the clinical diagnosis [6-18].

The treatment of patellofemoral condropathy is mostly conservative. In addition to careful functional re-education, the use of chondroprotectors may be useful. Under this term medicines and supplements are grouped as substances able to counteract the degenerative processes, favoring the normalization of the articular cartilage and the synovial fluid in which it is immersed and from which it draws nourishment and protection. More specifically, chondroprotectors are compounds capable of expressing one or more of the following characteristics: stimulating chondrocytes in the production of new cartilaginous matrix, stimulating synoviocytes in the synthesis of hyaluronic acid, inhibiting cartilage degradation by chondrolytic enzymes and preventing fibrin formation in the subchondral and synovial vasculature [19]. Among the most studied and used chondroprotectors are listed hyaluronic acid, glucosamine, chondroitin sulfate (galactosaminglucuronoglycan sulfate), hydrolyzed collagen, methylsulfonylmethane (MSM). In particular, the infiltrations of hyaluronic acid are used in the conservative treatment of patellofemoral chondropathies. This technique, tested for the first time in the early 1970s, involves intra-articular injection of sodium hyaluronate. Since then, international studies and extensive case studies have confirmed the effectiveness of infiltration of hyaluronic acid, especially in the treatment of condrophaty. Intra-articular injection of hyaluronic acid is also known as viscos-supplementation, referring to the viscoselastic properties of this substance. Not all the studies agree on the efficacy of hyaluronic acid infiltration in conservative treatment: some meta-analyses have even shown efficacy only slightly higher than with placebo. Other studies have established that the infiltration of hyaluronic acid produces a pain reduction comparable to that of intra-articular injections of cortisone [20].

These finding s highlight the need of further investigations to treat the patellofemoral chondropathies.

The aim of the study is to evaluate the efficacy and tolerability of the medical device "Bioart" in patients with gonarthrosis. Bioart is a native equine collagen-based device designed to improve the viscos-elasticity of the synovial fluid of the osteoarthritic knee and the consequent functional limitation, associated with degenerative phenomena of the joints caused by age, bad posture, traumas or concomitant chronic diseases. It is indicated in the treatment of osteoarthritis, in acute or chronic inflammation of the synovial membrane, acting mainly with a lubricating action and as mechanical protection on the synoviocytes of the articular cartilage, preventing damage to mechanical stressed cells (http://www.euroresearch.biz/ bioart/).

\section{Materials and methods}

\section{Study population}

Twenty-five patients (18 males and 7 females, with a mean age of $50.7 \pm 8.4$ years) with $1^{\text {st }}, 2^{\text {nd }}$ and $3^{\text {rd }}$ grade chondropathy, according to the Kellgren-Lawrence Scale (see next paragraph), were recruited to receive an intra-articular infiltration of Bioart (200 $\mathrm{mg}$ in $2-4 \mathrm{ml}$ of sterile saline solution) every 7 days, for a total of three infiltrations (http://www.euroresearch.biz/ bioart/).

The procedures followed have been approved by an Ethics committee (in accordance with ethical standards on human experimentation and with the Helsinki Declaration of 1975, as revised in 1983).

All patients were informed of the study's purposes and procedures and were asked to give their written informed consent. Patients were informed of their right to leave the study at any time. Standard procedures were implemented in order to fully guarantee patient privacy. Patients' personal data were used and stored in compliance with the principles of privacy protection set forth in former Legislative Decree no. 196 of 30 June 2003, subsequent Law 675/1996 and other applicable regulations. This information sheet concerned the personal data sent by patients at recruitment and those obtained during medical history procedures, physical examination and clinical tests. The data were disclosed in compliance with the provisions set forth in Ministerial Circular no. 6 of 2 September 2002 concerning the activities of ethics committees established pursuant to Ministerial Decree of 18 March 1998 (Official Gazette no. 214 of 12 September 2002).

Upon inclusion in the study, all the patients responded to 2 questionnaires intended to define their grade of inability caused by the chondropathy. The WOMAC (Western Ontario 
and McMaster Universities Osteoarthritis Index) score for lower limb pain, stiffness and physical function (Table 1) and the Lequesne Index for functional limitations were used. WOMAC is probably the most commonly used test utilised to assess the results of treatment for knee conditions. Each WOMAC item has 5 potential responses (from "none" to "very great"). The Lequesne Index assigns a score to each answer up to a total that is recorded and represents the reference value for the subsequent assessment. These evaluations are performed before the start of treatment and at 12 weeks.

Table 1: Western Ontario and McMaster Universities Osteoarthritis Index (WOMAC) score.

\begin{tabular}{|c|c|c|c|c|c|c|}
\hline \multirow[t]{5}{*}{ Pain } & Walking on a flat surface & 0 & 1 & 2 & 3 & 4 \\
\hline & Walking up and down stairs & 0 & 1 & 2 & 3 & 4 \\
\hline & Sleeping & 0 & 1 & 2 & 3 & 4 \\
\hline & Sitting or lying & 0 & 1 & 2 & 3 & 4 \\
\hline & Standing & 0 & 1 & 2 & 3 & 4 \\
\hline \multirow[t]{2}{*}{ Joint stiffness } & At first waking & 0 & 1 & 2 & 3 & 4 \\
\hline & Later in the day & 0 & 1 & 2 & 3 & 4 \\
\hline \multirow[t]{17}{*}{ Physical function } & Going down stairs & 0 & 1 & 2 & 3 & 4 \\
\hline & Going up stairs & 0 & 1 & 2 & 3 & 4 \\
\hline & Rising from sitting & 0 & 1 & 2 & 3 & 4 \\
\hline & Standing & 0 & 1 & 2 & 3 & 4 \\
\hline & Bending down & 0 & 1 & 2 & 3 & 4 \\
\hline & Walking on a flat surface & 0 & 1 & 2 & 3 & 4 \\
\hline & Getting into/out of the car & 0 & 1 & 2 & 3 & 4 \\
\hline & Going shopping & 0 & 1 & 2 & 3 & 4 \\
\hline & Putting on socks or tights & 0 & 1 & 2 & 3 & 4 \\
\hline & Taking off socks or tights & 0 & 1 & 2 & 3 & 4 \\
\hline & Getting out of bed & 0 & 1 & 2 & 3 & 4 \\
\hline & Lying in bed & 0 & 1 & 2 & 3 & 4 \\
\hline & Getting into/out of the bath & 0 & 1 & 2 & 3 & 4 \\
\hline & Sitting & 0 & 1 & 2 & 3 & 4 \\
\hline & Getting onto/off the toilet & 0 & 1 & 2 & 3 & 4 \\
\hline & Doing heavy domestic duties & 0 & 1 & 2 & 3 & 4 \\
\hline & Doing light domestic duties & 0 & 1 & 2 & 3 & 4 \\
\hline
\end{tabular}

All patients underwent a physical examination to establish whether they met the criteria for patellofemoral chondropathy, according to the Kellgren-Lawrence Scale. At inclusion, each patient presented recent radiographic images of the affected joint/s.This material was graded using the Kellgren and Lawrence system.

This system considers 4 stages of osteoarthritis: Stage I: initial, non-determinable joint space narrowing with the possible presence of bone spurs; Stage II: bone spurs and potential joint space narrowing; Stage III: moderate osteophytosis, clearly-defined joint space narrowing, subchondral sclerosis and potential subchondral bone deformation; Stage IV: severe osteoarthritis. The study included patients with clinically- and radiographically-confirmed Stage I, II, III patellofemoral chondropathy (according to Kellgren-
Lawrence). No proprioception tests investigating the articular function were performed on patients before or after the treatment.

\section{Patients treatment}

The patients enrolled in the study did not report any previous knee surgery or previous or current documented rheumatic or autoimmune diseases.

Before the start of treatment, all patients underwent an orthopedic examination. Post-treatment joint status (3 months) was assessed by ultrasound and magnetic resonance imaging. Moreover, during the treatment, patients did not undergo any rehabilitation protocols.

Having arranged the patient in a supine position, with the knee involved slightly flexed using a popliteal pillow and after thorough disinfection of the skin (alcohol or iodinebased antiseptic), $200 \mathrm{mg}$ of Bioart mixed with physiological solution were injected into the affected joint. In patients with I degree chondropathy, the intraarticular injection of Bioart was repeated twice a week. In patients with II and III degree chondropathy, the intra-articular injection was repeated three times a week apart.

\section{Statistical analysis}

The sample size was calculated on the basis of the $95 \%$ Confidence Interval (CI) precision of the primary outcome. More specifically, 20 patients were required to obtain an estimate precision of 0.11 of the estimated standard deviation, considering the absence of information on the outcome. The results are expressed as mean \pm Standard Deviation (SD). Data were tested for normality using the Kolmogorov-Smirnov test. Differences between before and after treatment for the whole population were evaluated using the paired $t$-test. When the assumptions for parametric test were not met, Wilcoxon signed-rank test was used. Differences are considered significant at a $\mathrm{p}$ value of $<0.05$.

\section{Results}

Twenty-three patients out of 25 completed the planned treatment period. None of the subjects had an adverse reaction to Bioart. All of them showed excellent tolerance of the treatment.

The patients' clinical characteristics are shown in Table 2. Of the 23 patients studied, 7 had grade I chondropathy (30\%), 13 grade II ( $57 \%)$ and 3 grade III $(13 \%)$.

As mentioned above, the WOMAC pain rating scale at baseline revealed a higher score in patients with grade II (44.4 \pm 9.7$)$ and grade III $(52.3 \pm 9.1)$ chondropathy, compared to those with grade I chondropathy $(29.4 \pm 5.7, \mathrm{p}<0.001)$. At the end of the cycle of infiltrations, all patients showed a significant reduction in WOMAC score (Figure 1), regardless of their age, gender and initial chondropathy grade. The average pretreatment score was $44.4 \pm 9.8(\min 22, \max 60)$ and the average post-treatment score was $25.7 \pm 9.0$ ( $\min 12$, max 47 ) (Figure 2 ). The difference between before and after the infiltration 
Table 2: Clinical and pathophysiological characteristics of subjects recruited in the study.

\begin{tabular}{|c|c|c|c|c|c|c|c|c|}
\hline Pat. No. & Initials & Date of birth & Gender & Classification & Anatomy & Limb & $\begin{array}{l}\text { Pre-treat. } \\
\text { WOMAN }\end{array}$ & $\begin{array}{c}\text { Post-treat. } \\
\text { WOMAC }\end{array}$ \\
\hline 1 & P.G. & 17/08/1958 & $\mathrm{F}$ & $2^{\text {nd }}$ grade chondropathy & Fragm. and fissuring & Right & 60 & 15 \\
\hline 2 & P.B. & 06/06/1958 & M & $1^{\text {st }}$ grade chondropathy & Oedema and softening & Left & 22 & 20 \\
\hline 3 & M.S. & $26 / 02 / 1947$ & M & $1^{\text {st }}$ grade chondropathy & Oedema & Right & 24 & 14 \\
\hline 4 & F.M. & 22/10/1979 & M & $2^{\text {nd }}$ grade chondropathy & Non-ext. multiple fissures & Right & 34 & 27 \\
\hline 5 & M.G. & 21/01/1971 & $\mathrm{F}$ & $2^{\text {nd }}$ grade chondropathy & Fragm. and fissuring & Left & 44 & 10 \\
\hline 6 & G.R. & $01 / 05 / 1960$ & M & $1^{\text {st }}$ grade chondropathy & Oedema & Left & 32 & 22 \\
\hline 7 & P.D. & 21/02/1950 & M & $1^{\text {st }}$ grade chondropathy & Oedema & Right & 27 & 13 \\
\hline 8 & M.A. & 19/11/1971 & M & $1^{\text {st }}$ grade chondropathy & Oedema and softening & Right & 36 & 19 \\
\hline 9 & G.P. & 06/05/1957 & M & $2^{\text {nd }}$ grade chondropathy & Fissuring & Left & 51 & 40 \\
\hline 10 & T.S. & 08/02/1975 & M & $2^{\text {nd }}$ grade chondropathy & Fragmentation & Left & 42 & 24 \\
\hline 11 & T.S. & 11/07/1972 & $\mathrm{F}$ & $3^{\text {rd }}$ grade chondropathy & Erosion & Right & 48 & 29 \\
\hline 12 & M.L. & 18/03/1980 & M & $2^{\text {nd }}$ grade chondropathy & Fragm. and fissuring & Left & 37 & 32 \\
\hline 13 & D.A. & $24 / 11 / 1968$ & M & $2^{\text {nd }}$ grade chondropathy & Multiple fissures & Left & 64 & 47 \\
\hline 14 & M.A. & 01/11/1970 & M & $1^{\text {st }}$ grade chondropathy & Oedema & Right & 35 & 16 \\
\hline 15 & M.A. & 05/03/1956 & M & $2^{\text {nd }}$ grade chondropathy & Fragm. and a few fissures & Right & 34 & 18 \\
\hline 16 & I.G. & $30 / 06 / 1963$ & $M$ & $2^{\text {nd }}$ grade chondropathy & Fissuring & Right & 58 & 34 \\
\hline 17 & V.E. & 16/11/1958 & $\mathrm{F}$ & $1^{\text {st }}$ grade chondropathy & Oedema & Left & 30 & 24 \\
\hline 18 & T.V. & $15 / 04 / 1964$ & $\mathrm{~F}$ & $3^{\text {rd }}$ grade chondropathy & Erosion & Right & 48 & 29 \\
\hline 19 & P.P. & 19/11/1953 & $M$ & $3^{\text {rd }}$ grade chondropathy & Erosion & Left & 61 & 35 \\
\hline 20 & F.F. & 29/10/1965 & M & $2^{\text {nd }}$ grade chondropathy & Fissuring & Right & 36 & 12 \\
\hline 21 & E.F. & $14 / 02 / 1971$ & $\mathrm{~F}$ & $2^{\text {nd }}$ grade chondropathy & Fissuring & Right & 29 & 25 \\
\hline 22 & A.M. & 19/11/1951 & $\mathrm{F}$ & $2^{\text {nd }}$ grade chondropathy & Fissuring & Left & 34 & 12 \\
\hline 23 & G.F. & $11 / 06 / 1975$ & M & $2^{\text {nd }}$ grade chondropathy & Fissuring & Right & 55 & 27 \\
\hline
\end{tabular}

treatment is statistically significant $(\mathrm{p}<0.001)$. Considering the initial clinical severity, all grades of chondropathy showed a similar improvement; more specifically, subjects with grade I chondropathy showed a post-treatment improvement in WOMAC score from $29.4 \pm 5.7$ to $18.2 \pm 5.0(-61 \%, \mathrm{p}<0.001)$, those with grade II chondropathy from $44.4 \pm 9.7$ to $24,8 \pm 7.3(-55 \%$, $\mathrm{p}<0.001)$, those with grade III chondropathy from $52.3 \pm 9.1$ to $31.0 \pm 4.2(-59 \%, \mathrm{p}<0.001)$ (Figure 3$)$.

As regards the Lequesne pain and dysfunction index, no significant difference was observed between the different grades of chondropathy at baseline (grade I $17.4 \pm 2.0$, grade II $18.5 \pm 1.1$, grade III 19.2 $\pm .0 .8, \mathrm{p}=\mathrm{ns}$ ). After treatment, all patients showed a score improvement, regardless of their gender, age or chondropathy grade. On average patients went from 18.0 \pm 1.1 to $10 \pm 1.2$ points $(\mathrm{p}<0.001)$ (Figure 4$)$. Already at follow-up after 12 weeks, 7 patients $(30 \%)$ showed a partial regression of chondropathy on MRI. A representative image of MRI before and after treatment is shown in Figure 5.

\section{Discussion}

The conservative treatment of patellofemoral condropathy has a well-documented background in the scientific literature of the last fifty years. The use of NSAIDs, cortisone drugs and chondroprotectors is common in conventional medicine.

The mechanism of action of corticosteroids is well established: inhibition of prostaglandin synthesis, reduction

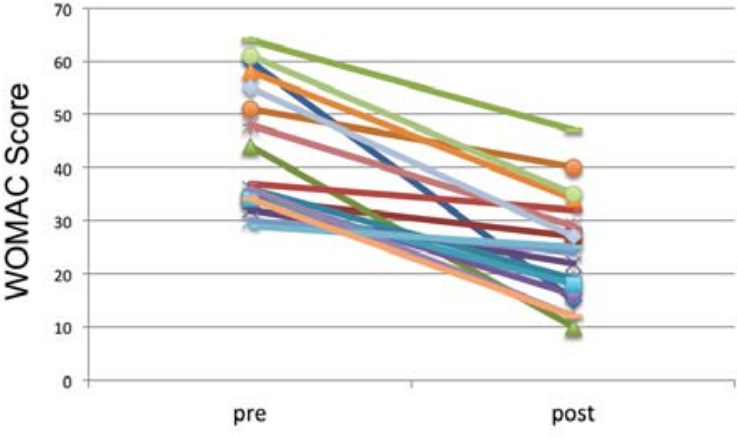

Figure 1: WOMAC score in 23 patients before and after BioArt treatment.

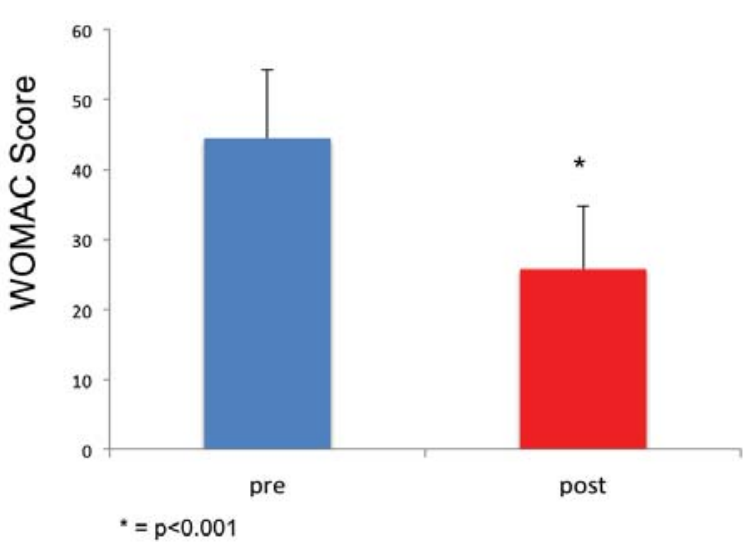

Figure 2: WOMAC Score pre- and post-BioArt treatment (average mean \pm SD)

Citation: Franzoni F, Fusi J, Ceccarelli M, Petrocchi A, Vitale M, et al. (2020) Treatment of patellofemoral chondropathy with BIOART. Arch Sports Med Physiother 5(1): 001-006. DOI: http://dx.doi.org/10.17352/asmp.000012 


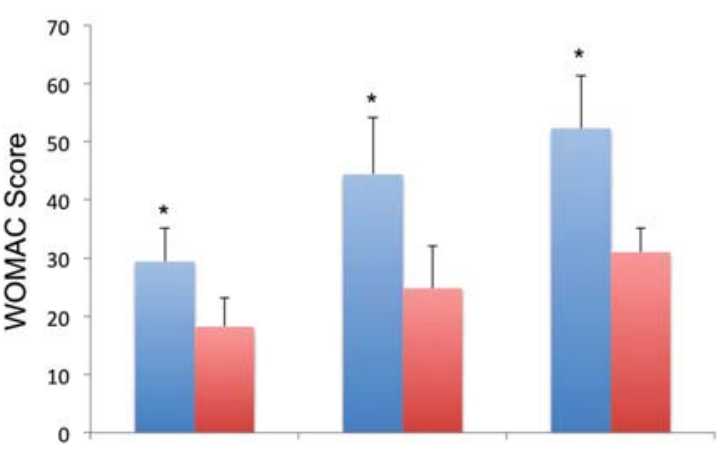

I grade II grade III grade

Figure 3: WOMAC Score pre- (left bars) and post (right bars)-BioArt treatment in relation to condrophathy severity (average mean $\pm S D$ ). ${ }^{*} \mathrm{P}<0.001$ versus pretreatment.

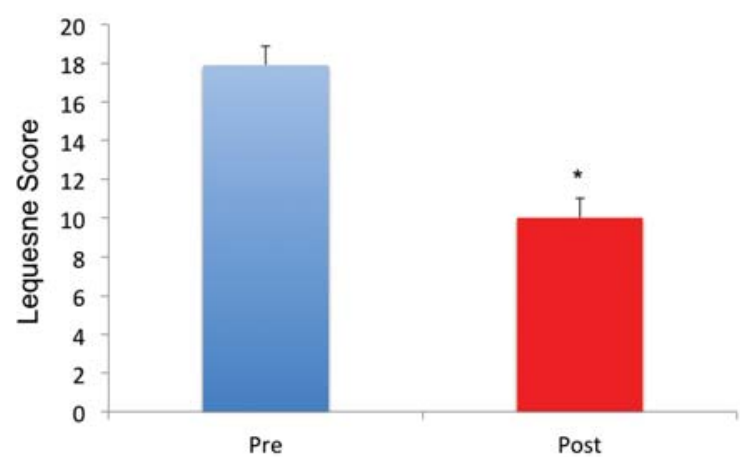

Figure 4: Lequesne Score pre- and post-BioArt treatment (average mean $\pm S D$ ). ${ }^{*} \mathrm{P}<0.001$ versus pre-treatment.

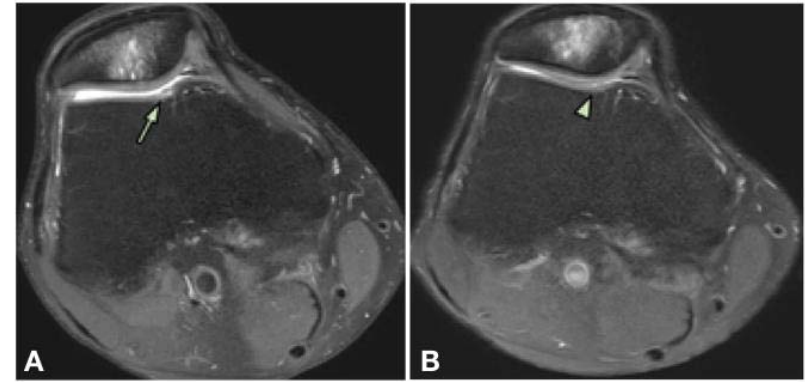

Figure 5: Axial image of knee obtained by magnetic resonance imaging before $(A)$ and after (B) treatment with Bioart.

of collagen and reduction in the production of IL-1, TNF and various proteases that attack cartilage. Fans and corticosteroids act only on pain symptoms. The use of chondroprotectors must be considered as a natural process, improving the protective, lubricating and "cushioning" effect of synovial fluid [22-23].

Recent studies have instead seen the use of platelet-rich plasma [24], which occurred effectively in the treatment of the syndrome.

The aim of our study was to verify the efficacy of Bioart, a device based on native equine collagen. The introduction of an articular equine collagen level aims to overcome, strengthen and protect the structures of cartilage, tendons, ligaments and joint capsule, improving the alignment of collagen fibers. It could be argued that the number of patients was limited to consider our results as relevant. Despite this, we have to highlight that in our study, all 23 patients showed a consistent improvement of the algic component and of the functional limitation strictly to the gonartrosic system during the considerate 12 weeks. The recorded data that are able to improve the clinical-functional picture of the treated patients with only 3. All patients are in fact recorded in a version of the medium-medium WOMAC 12 weeks after joint treatment, stiffness and functionality.

The use of a painless and very easy therapy (only one treatment / week) has expired.

\section{References}

1. Ficat P, Hungerford DS (1977) Disorders of the patellofemoral joint. Paris Masson 127.

2. Tanamas SK, Teichtahl AJ, Wluka AE, Wang Y, Davies-Tuck M, et al. (2010) The associations between indices of patellofemoral geometry and knee pain and patella cartilage volume: a cross sectional study. BMC Musculoskelet Disord 11: 87. Link: https://bit.ly/2Jr6FnH

3. Grelsamer RP, Bazos AN, Proctor CS (1993) Radiographic analysis of patellar tilt. J Bone Joint Surg Br 75: 822-824. Link: https://bit.ly/3myOgUq

4. Wittstein JR, O'Brien SD, Vinson EN, Garrett WE (2009) MRI evaluation of anterior knee pain: predicting response to nonoperative treatment. Skeleta Radiol 38: 895-901. Link: https://bit.ly/2JBnAnm

5. Brownstein BA, Lamb RL, Mangine RE (1985) Quadriceps torque and integrated electromyography. J Orthop Sports Phys Ther 6: 309-314. Link: https://bit.ly/3fWjbqY

6. Carson WG, James SL, Larson LR, Singer KM, Winternitz WW (1984) Patellofemoral disorders: physicals and radiographic examination Part I: Physical examination. Clin Orthop Relat Res 178-186. Link: https://bit.ly/2JAuRUi

7. Ferret JM (2006) Syndrome rotulien et isocnetisme. International Association Laser Therapy. Bergamo.

8. Grabiner MD, Koh TJ, Andrish JT (1992) Decreased excitation of vastus medialis oblique and vastus lateralis in patellofemoral pain. Eur $\mathrm{J}$ Exp Muscolo-skel Res 1: 33-37.

9. Grood ES, Suntry WS, Noyea FR, Boiler DL (1984) Biomechanics of the knee extension exercise. Effect of cutting the anterior cruciate ligament. J Bone Joint Surg 66: 725-734. Link: https://bit.ly/39yxp0j

10. Huberti HH, Hayes WC (1984) Patellofemoral contact pressures. The influence of Q-angle and tendofemoral contact. J Bone Joint Surg 66A: 715-724. Link: https://bit.ly/37owLzL

11. Insall JN, Aglietti P, Cerulli G (1983) Patellar pain and incongruency. Clin Orthop 217-224. Link: https://bit.ly/3IBtO40

12. Insall JN, Falvo KA, Wise DW (1976) Chondromalacia patellae: a prospective study. J Bone Joint Surg 58A: 1-6. Link: https://bit.ly/36vsKdi

13. Kennedy JC, Alexander IJ, Hayes KC (1982) Nerve supply on the human knee and its functional importance. Am J Sports Med 10: 329-335. Link: https://bit.ly/2VpcSD9

14. Kettelkamp DE (1981) Current concepts review: management of patellar malalignement. J Bone Joint Surg 63: 1344-1348.

15. Mizuno Y, Kumagai M, Mattessich SM, Elias JJ, Ramrattan N, et al. (2001) Q-angle influences tibiofemoral and patellofemoral kinematics. J Orthop Res19: 834-840. Link: https://bit.ly/3fVVI9B 
16. Outerbridge RE (1964) Further studies on the etiology of chondromalacia patellae. J Bone Joint Surg 46: 179. Link: https://bit.ly/39uZNjP

17. Patel D (1986) Plica as a cause of anterior knee pain. Orthop Clin North Am 17: 273- 277. Link: https://bit.ly/36vhIF7

18. Roels J, Martens M, Mulier JC (1978) Patellar tendonitis (jumper's knee). Am J Sports Med 6: 362-368. Link: https://bit.ly/3ojWeBf

19. Atanda A, Ruiz D, Dodson CC, Frederick RW (2012) Approach to the active patient with chronic anterior knee pain. Phys Sportsmed 40: 41-50. Link: https://bit.ly/36wbc0Z

20. Hart JM, Kuenze C, Norte G, Bodkin S, Patrie J, et al. (2019) Prospective, Randomized, Double-Blind Evaluation of the Efficacy of a Single-Dose Hyaluronic Acid for the Treatment of Patellofemoral Chondromalacia. Orthop J Sports Med 7. Link: https://bit.ly/33BYXOI
21. Rombouts JJ (1998) Traumatolgie du sport. In: L'enfant et le sport. Thiebaud M., Sprumont P. De Boeck Université (Ed). Bruxelles.

22. Poddar SK, Widstrom L (2017) Nonoperative Options for Management of Articular Cartilage Disease. Clin Sports Med 36: 447-456. Link: https://bit.ly/2JFdrFZ

23. Post WR, Dye SF (2017) Patellofemoral Pain: An Enigma Explained by Homeostasis and Common Sense. Am J Orthop (Belle Mead NJ) 46: 92-100. Link: https://bit.ly/37oy5Tf

24. Torrero JI, Aroles F, Ferrer D (2012) Treatment of knee chondropathy with platelet rich plasma. Preliminary results at 6 months of follow-up with only one injection. J Biol Regul Homeost Agents 26: 71S-78S. Link: https://bit.ly/33zbNwV
Discover a bigger Impact and Visibility of your article publication with Peertechz Publications

\section{Highlights}

* Signatory publisher of ORCID

- Signatory Publisher of DORA (San Francisco Declaration on Research Assessment)

* Articles archived in worlds' renowned service providers such as Portico, CNKI, AGRIS, TDNet, Base (Bielefeld University Library), CrossRef, Scilit, J-Gate etc.

* Journals indexed in ICMJE, SHERPA/ROMEO, Google Scholar etc.

* OAI-PMH (Open Archives Initiative Protocol for Metadata Harvesting)

* Dedicated Editorial Board for every journal

* Accurate and rapid peer-review process

* Increased citations of published articles through promotions

* Reduced timeline for article publication

Submit your articles and experience a new surge in publication services (https://www.peertechz.com/submission).

Peertechz journals wishes everlasting success in your every endeavours.

Copyright: @ 2020 Franzoni F, et al. This is an open-access article distributed under the terms of the Creative Commons Attribution License, which permits unrestricted use, distribution, and reproduction in any medium, provided the original author and source are credited.

Citation: Franzoni F, Fusi J, Ceccarelli M, Petrocchi A, Vitale M, et al. (2020) Treatment of patellofemoral chondropathy with BIOART. Arch Sports Med Physiother 5(1): 001-006. DOI: http://dx.doi.org/10.17352/asmp.000012 